\title{
An empirical behavioral model of households' deposit dollarization
}

WORKING PAPER SERIES

No. 67 / December 2020

Ramis Khabibullin

Alexey Ponomarenko 


\section{Ramis Khabibullin}

Research and Forecasting Department, Bank of Russia. Email: KhabibullinRA@cbr.ru

\section{Alexey Ponomarenko}

Research and Forecasting Department, Bank of Russia. Email: PonomarenkoAA@cbr.ru

We are grateful to Karsten Kohler, participants of the Second Behavioral Macroeconomics Workshop in Bamberg, participants of the VI Modern Econometric Tools and Applications conference in Nizhny Novgorod and participants of Bank of Russia Workshop 'Recent Trends in the Central Bank Macroeconomic Modeling' for their valuable comments and suggestions.

Bank of Russia Working Paper Series is anonymously refereed by members of the Bank of Russia Research Advisory Board and external reviewers.

Cover image: Shutterstock.com

\section{(C) Central Bank of the Russian Federation, 2020}

Address: $\quad 12$ Neglinnaya street, Moscow, 107016

Tel.: $\quad$ +7 $\quad$ 495 771-91-00, +7 495 621-64-65 (fax)

Website: $\quad$ www.cbr.ru

All rights reserved. The views expressed in this paper are solely those of the authors and do not necessarily reflect the official position of the Bank of Russia. The Bank of Russia assumes no responsibility for the contents of the paper. Any reproduction of these materials is permitted only with the express consent of the authors. 


\section{Abstract}

We use the behavioral concept to endogenously model the evolution of the link between households' deposit dollarization and exchange rate developments in Russia. We estimate the model empirically and show that the reaction of households to exchange rate appreciation weakens when exchange rate developments become more volatile. The proposed model outperforms the contemporary nonlinear time series models in forecasting the changes in dollarization during the Bank of Russia's transition to a flexible exchange rate regime.

JEL-classification: C11, D84, E44, G17

Keywords: Dollarization, behavioral finance, variational Bayes, Russia 


\section{Introduction}

Deposit dollarization has always been an important feature of the Russian economy. The hyperinflation that occurred in the early 1990s and the currency crisis of 1998 increased the demand for foreign currency-linked deposits for holding savings. In subsequent years, periods of extensive de-dollarization in times of ruble appreciation have alternated with renewed shifts to foreign currency-linked deposits in times of ruble depreciation (e.g. during the financial crisis of 2008) presumably providing the indications of the speculative behavior of households.

Notably, prior to 2015 the Bank of Russia adhered to a managed exchange rate strategy and conducted foreign exchange interventions trying to smooth exchange rate fluctuations. In 2015 the Bank of Russia transitioned to a fully flexible exchange rate regime and the volatility of ruble's exchange rate's fluctuations increased significantly. Interestingly (and somewhat surprisingly), in this environment the changes in household's deposits dollarization in 2015-2018 seem to have detached from the observed exchange rate development, implying an evidently time-varying link between the variables.

This is a notable observation considering that the policymakers in the emerging markets are occasionally fearful that in an environment of deposit dollarization substantial exchange rate movements may result in extrapolative destabilizing re-denomination of the currency of deposits. Arguably, this consideration may be regarded as a reason of a "fear of floating" (i.e. reluctance to adopt a flexible exchange rate regime). Therefore, it is generally important to conduct a comprehensive analysis of the aforementioned case.

In order to model and predict the evolution of the relationship between exchange rate movements and deposit dollarization we set up a behavioral model that allows the households to switch between different strategies. The alternative strategies adopt either extrapolating or mean-reversing expectations regarding the exchange rate developments. Presumably, this feature may be used to account for the fact that increased exchange rate volatility may discourage adaptive expectations and mute households' reaction to realized exchange rate depreciation.

We empirically estimate the model using the novel stochastic gradient variational Bayes with normalizing flows method. The model's performance is evaluated via a forecasting exercise and compared with the results obtained by employing a set of contemporary nonlinear time series models. The results indicate that the behavioral elements facilitated the model's faster adjustment to the new environment while the non- 
structural models required a relatively large number of observations to alter the parameters for the new regime. As far as we know this is a pioneering example of a practical application of behavior finance concepts in this area.

The paper is structured as follows. Section 2 briefly discusses the dollarization and exchange rate developments in Russia. Section 3 outlines the behavioral model. Section 4 describes the alternative time series models. Section 5 presents the results of the forecasting exercise. Section 6 concludes.

\section{Exchange rate policy and dollarization developments in Russia: some stylized facts}

Starting from 1999 to 2014 the Bank of Russia implemented exchange rate policy under the managed floating exchange rate regime, although it gradually decreased its influence on the exchange rate dynamics.

In 2005, the Bank of Russia introduced the dual-currency basket as the operational indicator of its exchange rate policy. The Bank of Russia set the corridor for this operational indicator (the operational band) and implemented foreign exchange interventions on its borders to curb the dual-currency ${ }^{1}$ basket's value fluctuations. In late 2008-early 2009, the Russian economy faced a large-scale external shock induced by sharp changes of the situation in global financial and commodity markets. In these circumstances, the Bank of Russia modified its exchange rate policy framework. In February 2009, the Bank of Russia set a rule for the automatic shift of the operational band conditionally on the accumulated amount of the Bank of Russia's FX interventions and fixed the width of this floating band at 2 rubles. Since then the width of the floating operational band has been gradually increased to ensure a shift to a more flexible exchange rate. In October 2010, the Bank of Russia announced that the fixed band for the ruble value of the dual-currency basket was abandoned.

Nevertheless, from October 2010 to 10 November 2014 the Bank of Russia still used the ruble value of the dual-currency basket as the operational indicator for exchange rate policy implementation. However, the operational band was now floating, its borders gradually adjusted depending on the amount of FX interventions, forming a

\footnotetext{
${ }^{1}$ The dual currency-basket is the weighted average of USD and euro with weights 0.55 and 0.45 accordingly.
} 
new wider target range for the dual-currency basket (see Bank of Russia 2013 for details). The evolution of the ruble exchange rate is shown in Figure 1. On 10 November 2014, the Bank of Russia abolished the exchange rate policy mechanism by cancelling the permissible range of the dual-currency basket ruble values (operational band) and regular interventions on and outside the borders of this band.

Figure 1. Ruble / dual-currency basket exchange rate

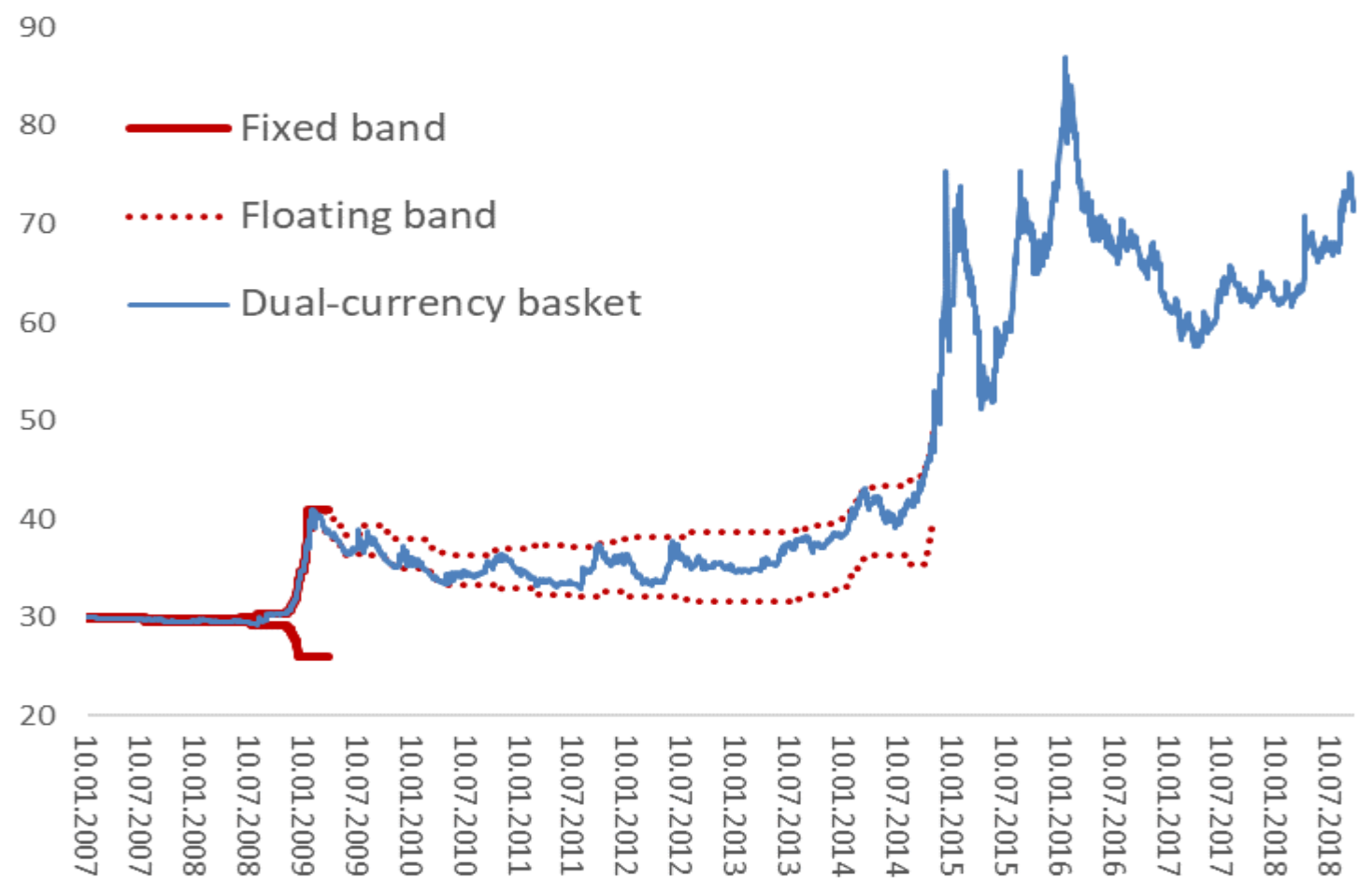

Notably, exchange rate fluctuations are commonly regarded as the driver of deposits dollarization (see e.g. Honohan 2007, Neanidis and Savva 2009). Presumably, depreciation of the national currency may result in an increase of dollarization due to households' adaptive expectations. Indeed, the ruble's gradual depreciation in 2008-2009 was associated with large inflows ${ }^{2}$ into foreign currency deposits (Figure 2). ${ }^{3}$

Interestingly (and somewhat surprisingly), the increase in volatility of exchange rate fluctuations in 2015-2016 did not translate into dramatic changes in households' deposits dollarization. In fact, in this environment the changes in household's deposits dollarization were insubstantial and seem to have detached from the observed exchange rate development, implying an evidently time-varying link between the variables. This

\footnotetext{
${ }^{2}$ See Section 3 for the description of the dollarization variable.

${ }^{3}$ A detailed discussion of dollarization developments in Russia prior to 2014 is provided in Ponomarenko et al. (2013).
} 
observation gives us the insight that we cannot rely on the assumption of linear adaptive expectations to model dollarization.

The idea that the linkage between exchange rate and dollarization developments is nonlinear is not useful. However, previous studies mostly focused on implementing the hysteresis effect (Kamin and Ericsson 2003, Feige 2003, Valev 2010, Samreth 2011). Barajas and Morales (2003) report that a pegged exchange rate regime encourages dollarization but do not offer the underlying model. Meanwhile, the aim of this paper is to provide a model that is able to capture the endogenous change in the sensitivity of dollarization to exchange rate developments during the transition to a different exchange rate regime.

Figure 2. Inflows into households' foreign currency deposits (sums over on 3-month rolling periods as a ratio to total deposits' stock), shaded areas are the periods of volatile ruble exchange rate fluctuations.

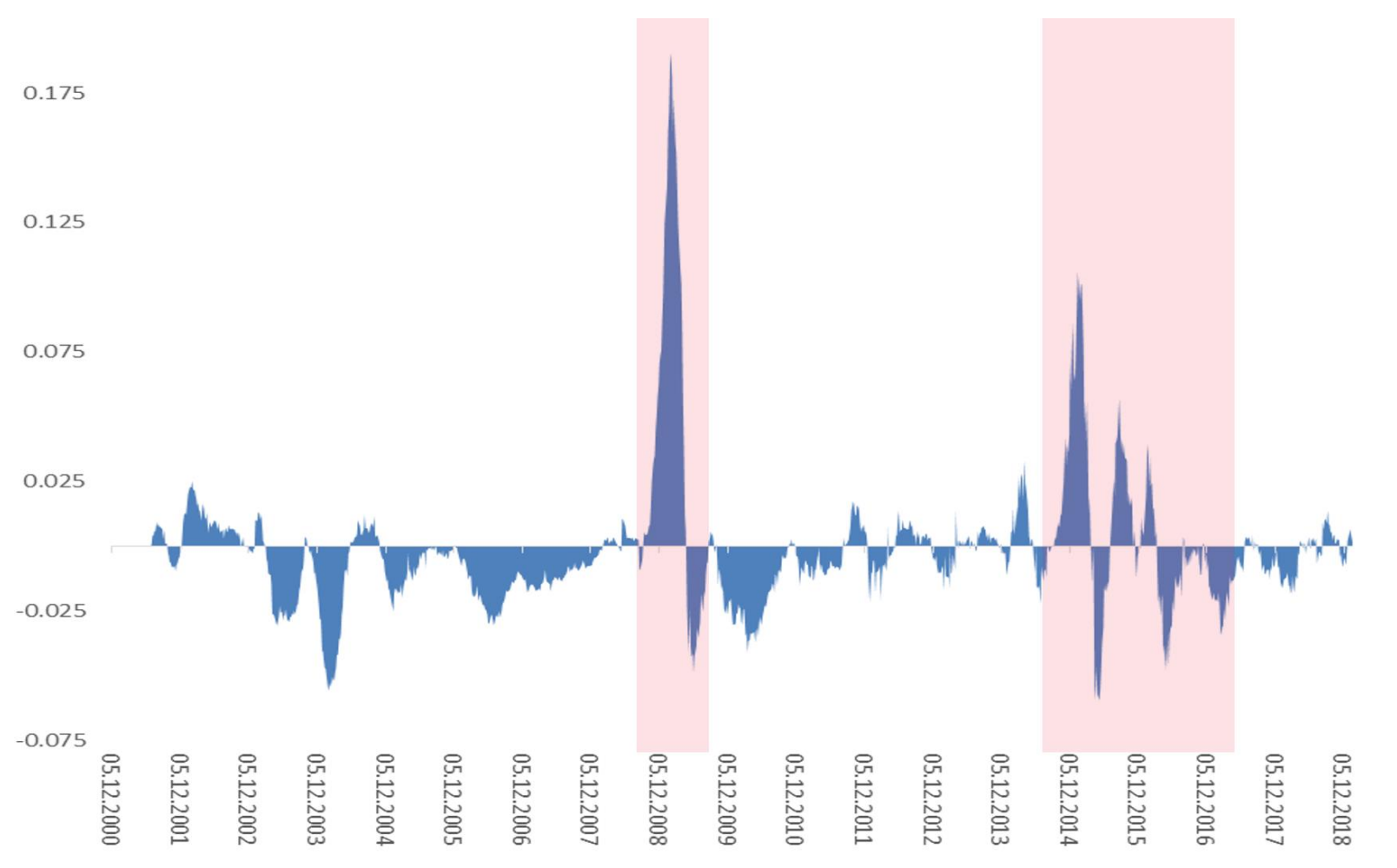

\section{The model}

Our approach is based on the conventional behavioral models of financial markets outlined by Westerhoff (2009) and Franke and Westerhoff (2012). The underlying idea is that agents tend to choose a strategy if it has seemingly been performing well recently. 
Presumably, this feature may be used to account for the fact that increased exchange rate volatility may discourage adaptive expectations and mute households' reaction to realized exchange rate depreciation. Accordingly, our model is specified as follows. ${ }^{4}$

There are two types of agents in the model conventionally labeled as fundamentalists and chartists. They choose the share of foreign currency-linked deposits in total deposits (which is called dollarization in our model). The agents choose the dollarization share basing on the observed oil price inflation, sentiment index, and exchange rate values. The oil price is generally regarded as an important economic fundamental that determines ruble's exchange rate. The sentiment index in our model represents a summary indicator of the mood of recent news releases on exchange rate and financial markets topics. If the majority of releases contains information which is assessed as negative by currency market participants, the sentiment index will be also negative and vice versa. The reaction to exchange rate developments is, naturally, the key research question of our paper and this where the alternative strategies are different.

The fundamentalists compare observed log exchange rate $e_{t}$ in the current ${ }^{5}$ period with its subjective 'fundamental value' $e_{t}^{\star}$, which follows a random walk process. Hence, their dollarization can be characterized by the following equations:

$$
\begin{gathered}
d_{t}^{f}=\alpha^{f}+\varphi\left(e_{t}^{*}-e_{t}\right)+\sum_{j=1}^{p}\left(b_{\text {oil.j }}^{f} \pi_{t-j}^{o i l}+b_{\text {sent.j }}^{f} s_{t-j}\right)+v_{t}^{f} ; v_{t}^{f} \sim N\left(0, \sigma_{f}^{2}\right) \\
e_{t}^{*}=e_{t-1}^{*}+v_{t}^{e *} ; \quad v_{t}^{e *} \sim N\left(0, \sigma_{e *}^{2}\right)
\end{gathered}
$$

where $\pi_{t}^{\text {oil }}$ - oil price inflation, $s_{t}$ - sentiment index, $e_{t}$ - log exchange rate, $e_{t}^{*}-$ fundamental log exchange rate value, $\alpha^{f}$ - constant, $p-$ number of lags. We set $p=3$ for all models.

The chartists make their decision based on the exchange rate growth:

$$
d_{t}^{c}=\alpha^{c}+\chi\left(e_{t}-e_{t-1}\right)+\sum_{j=1}^{p}\left(b_{o i l . j}^{c} \pi_{t-j}^{o i l}+b_{\text {sent.j }}^{c} s_{t-j}\right)+v_{t}^{c} ; \quad v_{t}^{c} \sim N\left(0, \sigma_{c}^{2}\right)
$$

\footnotetext{
${ }^{4}$ We describe a comprehensive empirical model in the section. However, a very simplistic version of such approach presented in Appendix $A$ is sufficient to produce the meaningful results.

${ }^{5}$ Given the 5-days data frequency it is not clear if we should assume that households react to contemporary or past changes in the exchange rate. Therefore, in the course of this study we have estimated both versions of the model. The version based on the contemporary exchange rates was selected due to forecasting performance but using a lagged depreciation rate does not change the results dramatically. In this respect the simplistic version of the model (Appendix A) that employs a lagged depreciation rate at daily frequency seems to be the most appropriate.
} 
We restrict parameters $\varphi$ and $\chi$ to be positive. The positive parameter $\varphi$ states that fundamentalists are assumed to use the following heuristic. If the observed exchange rate is lower (higher) than the 'fundamental' value, fundamentalists predict that it will rise (fall) in the future. Hence, the fundamentalists would buy (sell) foreign currency-linked deposits and increase (decrease) their dollarization.

The positive parameter $\chi$ means that chartists are assumed to buy currency once they observe an increase in exchange rate during the last 5 days and sell it if the decrease was observed.

The share of the fundamentalists in the total number of market participants depends on the relative profitability of the fundamentalists' strategy compared to the chartists' one. The hypothetical wealth for each strategy is determined as:

$$
w_{t}^{\text {type }}=\eta w_{t-1}^{\text {type }}+(1-\eta)\left(e_{t-1}-e_{t-2}\right) d_{t-1}^{\text {type }} ; \text { type }=\{f, c\}
$$

This equation means that the wealth for each type depends on the previous wealth and on the profitability of the previous dollarization choice. The initial values of wealth are set to be equal: $w_{0}^{f}-w_{0}^{c}=0$. The value of this wealth gap affects hidden state $a_{t}$, which is discussed below.

The share of fundamentalists is defined by the following equation:

$$
s f_{t}=\left(1+\exp \left(-\beta a_{t}\right)\right)^{-1}
$$

where $\beta$ - unrestricted coefficient.

Following Franke and Westerhoff (2012), we considered two forms of fundamentalists' share specifications ${ }^{6}$ :

$$
\begin{gathered}
a_{t}=\left(w_{t}^{f}-w_{t}^{c}\right) \\
a_{t}=\left(w_{t}^{f}-w_{t}^{c}\right)+\rho_{\text {herd }}\left(w_{t-1}^{f}-w_{t-1}^{c}\right)
\end{gathered}
$$

The abbreviation WG stands for the specification, in which only the contemporaneous wealth gap affects the fundamentalists share. HERD is the model with herding: the previous wealth gap affects the current one. We restrict parameter $\rho_{\text {herd }}$ to produce a stationary process for $a_{t}: 0 \leq \rho_{\text {herd }}<1$.

We fit the observed 5-day changes in total dollarization $d d_{t}$ :

$$
\begin{gathered}
\bar{d}_{t}=s f_{t} d_{t}^{f}+\left(1-s f_{t}\right) d_{t}^{c} \\
d d_{t}=\bar{d}_{t}-\bar{d}_{t-1}
\end{gathered}
$$

\footnotetext{
${ }^{6}$ In the original paper the herding term was written as the difference between the shares of fundamentalists and chartists: $($ share $($ fund $)-\operatorname{share}($ chart $))=s f_{t}-\left(1-s f_{t}\right)$. However, due to computational complexity we changed it to the autoregression version.
} 
It means that in each period total dollarization is the weighted average of two types of agents' choice.

\subsection{The estimation technique}

The proposed model has nonlinear state-space representation. To our knowledge it is common to estimate such models using particle filters (Lux 2018), method of simulated moments (Franke and Westerhoff (2012)) or machine learning surrogate filters (Lamperti et al (2018)). In this paper we use the stochastic gradient variational Bayes with mean field approximation approach (Beal 2003, Rezende and Mohamed 2015, Khabibullin and Seleznev 2020). This approach is a powerful tool for the estimation of complex non-linear models similar to those presented in this paper model. Similar methods have previously been applied to agent-based models (Di Guilmi et al. 2008, 2020). We use this approach not only to estimate posterior parameters densities but to choose prior hyperparameters values.

The technique is based on the stochastic maximization of the evidence lower bound (ELBO) with respect to prior hyperparameters and approximation density:

$$
L\left(q_{\lambda}, \psi\right)=\log p(y \mid x, \psi)-K L\left(q_{\lambda}(\theta)|| \log p(\theta \mid y, x, \psi)\right) \rightarrow \max _{\psi, q 0}
$$

where $\theta$ - vector of parameters and latent states, $\psi$ - hyperparameters vector, $q_{\lambda}(\cdot)-$ approximation density, $\lambda$ - parameters of this density, $p(\theta \mid y, x, \psi)-$ posterior parameters and states density, $p(y \mid x, \psi)$ - marginal likelihood.

Under the mean-field approach it is assumed that approximation density is independent across parameter blocks. In case of the proposed behavioral model this approximation density function is the following:

$$
\begin{aligned}
q_{\lambda}(\theta)=q_{N}( & \left.\boldsymbol{B} \mid \boldsymbol{\mu}_{\boldsymbol{B}}, \boldsymbol{\Sigma}_{\boldsymbol{B}}\right) \times q_{N}\left(\beta \mid \mu_{B}, \sigma_{B}\right) \times q_{N}\left(\rho_{\text {herd }} \mid \mu_{\rho}, \sigma_{\rho}\right) \times q_{\lambda_{\eta}}(\eta) \times q_{I G}\left(\sigma_{c}^{2} \mid v_{c}, b_{c}\right) \\
& \times q_{I G}\left(\sigma_{f}^{2} \mid v_{f}, b_{f}\right),
\end{aligned}
$$

where $q_{N}\left(\cdot \mid \mu_{i}, \Sigma_{i}\right)$ - normal density function with mean $\mu_{i}$ and covariance matrix $\Sigma_{i}$ hyperparameters. $q_{I G}\left(\cdot \mid v_{i}, \mathrm{~b}_{i}\right)$ - inverse-Gamma density function with shape $v_{i}$ and scale $b_{i}$ hyperparameters. $\boldsymbol{B}=\left[a^{f}, a^{c}, \chi, \varphi,\left\{b_{i j}^{r}\right\}_{i \in\{\text { oil,sent }\} ; r \in\{c, f\} ; j=1 \ldots p}\right]^{\prime}$. 


\subsection{The data and the set-up of the experiment}

We use the dataset of 5-day frequency from January 2002 till January 2019.

The dollarization variable is constructed as follows:

$$
\begin{gathered}
d d_{t}=\frac{F D_{t}-F D_{t-1} \times \frac{E_{t}}{E_{t-1}}-\frac{F D_{t-1}}{T D_{t-1}} \times \Delta D_{t}}{T D_{t-1}}, \\
\Delta D_{t}=\Delta R D_{t}+F D_{t}-F D_{t-1} \times \frac{E_{t}}{E_{t-1}},
\end{gathered}
$$

where $T D_{t}-$ total households deposits, $F D_{t}-$ ruble value of households deposits denominated in foreign currency, $R D_{t}$ - households deposits denominated in rubles, $E_{t}$ - ruble/USD exchange rate value. The rationale behind this transformation is as follows. The term $F D_{t}-F D_{t-1} \times \frac{E_{t}}{E_{t-1}}$ represents the increase in foreign currency deposits (approximately controlling for the re-evaluation effect). $\Delta D_{t}$ represents the increase in total households' deposits (approximately controlling for the re-evaluation effect). The term $\frac{F D_{t-1}}{T D_{t-1}} \times \Delta D_{t}$ represents the projected inflow into foreign currency deposits given the observed deposits expansion rate ${ }^{7}$ and their past composition. Accordingly, the nominator shows the deviation of the actual inflows into foreign currency deposits from the extrapolated value and represents the changes in the households' behavior. The denominator scales this value dividing it by the amount of total deposits.

Oil price inflation $\left(\pi_{t}^{o i l}\right)$ is calculated as the percentage change of the Brent index published by FRED.

The exchange rate variable $\left(e_{t}\right)$ is the ruble/USD exchange rate provided by the Bank of Russia.

The sentiment index $\left(s_{t}\right)$ is estimated by the Bank of Russia based on daily news releases on exchange rate and financial market topics.

To make a forecasting exercise we split the whole sample into train and test samples in the following manner. We first estimate the behavioral model on the sample till the $15^{\text {th }}$ of September 2009 and calculate forecasts on horizon $h$, starting from the $20^{\text {th }}$ of September 2009. We proceed by recursively adding new observations to the train sample and moving the rolling test sample accordingly. At each step we re-estimate the model and calculate out-of-sample forecasts for the new train sample. The forecasts are

\footnotetext{
${ }^{7}$ Controlling for monetary expansion is a traditional approach in modelling dollarization (see e.g. Honohan 2007, Neanidis and Savva 2009).
} 
estimated conditionally on the actual values of oil prices, sentiment index and exchange rate in the test sample.

\section{Benchmark models}

In order to assess the practical usefulness of our approach we compare the forecast errors of the behavioral model with those obtained via the same exercise with the collection of time series models. These are state-of-the-art nonlinear models that also have the capacity to capture the time-varying link between dollarization and exchange rate depreciation.

\section{1 $\quad$ Autoregression model}

The simplest possible benchmark model for comparison is the standard autoregression with exogenous variables $\operatorname{ARX}(4)$ model in the following form:

$$
d d_{t}=A^{c}+\sum_{j=1}^{p} A^{y \cdot j} d d_{t-j}+\sum_{j=1}^{p} \boldsymbol{X}_{t-j}^{\prime} A^{x \cdot j}+A^{e .0} \Delta e_{t}+\varepsilon_{t} ; \varepsilon_{t} \sim N\left(0, \sigma_{d d}^{2}\right)
$$

where vector of exogenous variables consists of: $\boldsymbol{X}_{\boldsymbol{t}}=\left[\pi_{t}^{\text {oil }}, \Delta e_{t}, s_{t}\right]^{\prime}$.

We estimate this model using the standard maximum likelihood method.

\subsection{Time-varying parameters autoregression model}

The proposed model has the feature of regime switching between fundamentalists' and chartists' strategies. Hence, standard models with endogenous regime switching and time-varying coefficients are natural benchmark models for comparison. The simplest possible benchmark for time-varying parameters is the following state-space model:

$$
\begin{gathered}
d d_{t}=A_{t}^{c}+\sum_{j=1}^{p} A_{t}^{y . j} d d_{t-j}+\sum_{j=1}^{p} \boldsymbol{X}_{\boldsymbol{t}-\boldsymbol{j}}^{\prime} \boldsymbol{A}_{\boldsymbol{t}}^{\boldsymbol{x} . \boldsymbol{j}}+A_{t}^{e .0} \Delta e_{t}+\varepsilon_{t} ; \varepsilon_{t} \sim N\left(0, \sigma_{d d . t}^{2}\right) \\
\boldsymbol{a}_{\boldsymbol{t}}=\boldsymbol{a}_{\boldsymbol{t}-\mathbf{1}}+\boldsymbol{v}_{\boldsymbol{t}} ; \boldsymbol{v}_{\boldsymbol{t}} \sim \boldsymbol{N}(\mathbf{0}, \boldsymbol{\Omega})
\end{gathered}
$$

where vector $a_{t}$ consists of all parameters of the equation (9.1TVP) except $\sigma_{d d . t}^{2}$.

Due to computational challenges we estimate this model using the forgetting factor approximation proposed by (Koop, Korobilis, 2013). The idea is to estimate parameters as: 


$$
\boldsymbol{a}_{\boldsymbol{t}} \mid I_{t-1} \sim N\left(\boldsymbol{a}_{(t \mid t-1)}, \boldsymbol{V}_{(t \mid t-1)}\right)
$$

where $I_{t-1}$ - information available at period $t-1, \boldsymbol{a}_{(t \mid t-1)}$ - state values calculated using standard Kalman Filter with modification of the state variance:

$$
\boldsymbol{V}_{(t \mid t-1)}=\lambda^{-1} \boldsymbol{V}_{(t \mid t)}
$$

Observation variance is calculated as follows:

$$
\sigma_{d d . t}^{2}=\kappa \times \sigma_{d d . t-1}^{2}+(1-\kappa) \hat{\varepsilon}_{t}^{2},
$$

where $\hat{\varepsilon}_{t}^{2}$ - squared residual terms for the observation equation. To estimate the model we need to also set initial conditions: $\sigma_{d d .0}^{2}=\alpha_{o b s} \operatorname{var}\left(d d_{\text {train }}\right), \boldsymbol{V}_{0 \mid 0}=\alpha_{s t} \boldsymbol{V}_{\text {ols }}$. Here $\operatorname{var}\left(d d_{\text {train }}\right)$ - a variance of the depended variable in the sample before the start of the test sample (the $20^{\text {th }}$ of September, 2009). $\boldsymbol{V}_{\text {ols }}$ is the diagonal matrix with a diagonal equal to the diagonal of the ordinary least squares parameters covariance matrix. Shares hyperparameters are restricted: $\alpha_{o b s} \in[0.05,1], \alpha_{s t} \in\left[0.001,10^{3}\right]$.

To choose hyperparameters values $\left[\kappa, \lambda, \alpha_{o b s}, \alpha_{s t}\right]$ we minimize the out-of-sample RMSE using the 'Bayesian Optimization' python package.

\subsection{Threshold vector autoregression}

Another method to take into account time-varying parameters is to assume regime switching. The first class of these models considered in this paper is the threshold vector autoregression model (TVAR):

$$
\begin{gathered}
\boldsymbol{Y}_{\boldsymbol{t}}=\boldsymbol{A}^{\boldsymbol{c}}\left(s_{t}\right)+\sum_{j=1}^{p} \boldsymbol{A}^{\boldsymbol{y} \cdot \boldsymbol{j}}\left(s_{t}\right) \boldsymbol{Y}_{\boldsymbol{t}-\boldsymbol{j}}+\sum_{j=1}^{p} \boldsymbol{A}_{\boldsymbol{t}}^{\boldsymbol{x} \cdot \boldsymbol{j}}\left(s_{t}\right) \boldsymbol{X}_{\boldsymbol{t}-\boldsymbol{j}}+\boldsymbol{\varepsilon}_{\boldsymbol{t}} \\
\boldsymbol{\varepsilon}_{\boldsymbol{t}} \sim N\left(0, \boldsymbol{\Sigma}\left(s_{t}\right)\right) \\
A^{k}\left(s_{t}\right)=\left\{\begin{array}{l}
A_{0}^{k}, \text { if } \mathbf{z}_{\boldsymbol{t}}^{\prime} \boldsymbol{\gamma} \leq \bar{z} \\
A_{1}^{k}, \text { if } \mathbf{z}_{\boldsymbol{t}}^{\prime} \boldsymbol{\gamma}>\bar{z}
\end{array} ; \sigma^{k}\left(s_{t}\right)=\left\{\begin{array}{l}
\sigma_{0}^{k}, \text { if } \mathbf{z}_{\boldsymbol{t}}^{\prime} \boldsymbol{\gamma} \leq \bar{z} \\
\sigma_{1}^{k}, \text { if } \mathbf{z}_{\boldsymbol{t}}^{\prime} \boldsymbol{\gamma}>\bar{z}
\end{array}\right.\right.
\end{gathered}
$$

where $s_{t}$ - current state, $z_{t}$ - threshold variable, which could be any observable variable or/and its lags, set of exogenous variables $\boldsymbol{X}_{\boldsymbol{t}}=\pi_{t}^{\text {oil }}$, set of endogenous variables $\boldsymbol{Y}_{\boldsymbol{t}}=\left[d d_{t}, \Delta e_{t}, s_{t}\right]^{\prime}$. We estimate this model using maximum likelihood method ${ }^{8}$.

The main rationale in using TVAR instead of univariate threshold autoregression is the fact that regime switching is estimated in a way to affect all endogenous variables in the model.

\footnotetext{
${ }^{8}$ We use the "TVAR" function from the "tsDyn" R package (Di Narzo, et al (2009)).
} 
We estimate two TVAR specifications. In the first specification (TVAR-E) we use lag of the currency rate change $\Delta e_{t-1}$ as the threshold variable. In the second specification (TVAR-SF) we use the recursively calculated variable $\widetilde{s f_{t}}$. This variable is the naïve fundamentalists' share, calculated using calibrated parameters. Detailed information on the naïve share calculation can be found in Appendix A.

\subsection{Smooth transition autoregression}

We also extend the previous benchmark with the specification with a smooth transition between states ${ }^{9}$ :

$$
\begin{gathered}
d d_{\boldsymbol{t}}=\boldsymbol{\mu}\left(s_{t}=1\right) \times G\left(\mathbf{z}_{\boldsymbol{t}}^{\prime} \boldsymbol{\gamma}-u\right)+\boldsymbol{\mu}\left(s_{t}=0\right) \times\left(1-G\left(\mathbf{z}_{\boldsymbol{t}}^{\prime} \boldsymbol{\gamma}-u\right)\right) \\
\boldsymbol{\mu}\left(s_{t}\right)=A^{c}\left(s_{t}\right)+\sum_{j=1}^{p-1} \boldsymbol{A}^{\boldsymbol{y} \cdot \boldsymbol{j}}\left(s_{t}\right) \boldsymbol{Y}_{\boldsymbol{t}-\boldsymbol{j}}+\sum_{j=1}^{p} \boldsymbol{A}_{\boldsymbol{t}}^{\boldsymbol{x} \boldsymbol{j}}\left(s_{t}\right) \boldsymbol{X}_{\boldsymbol{t}-\boldsymbol{j}}+A^{e .0}\left(s_{\mathrm{t}}\right) \Delta e_{t}+\boldsymbol{\varepsilon}_{\boldsymbol{t}} \\
\boldsymbol{\varepsilon}_{\boldsymbol{t}} \sim N\left(0, \boldsymbol{\Sigma}\left(s_{t}\right)\right)
\end{gathered}
$$

where $G(\cdot)$ - is the prespecified smooth function. We choose this function to be a simple sigmoid function, $u_{t}$ - threshold cutoff, which is of the optimized parameters. We also consider two specifications depending on threshold variable: (1) lag of the currency rate change (STAR E); (2) naïve fundamentalists' share (STAR SF).

\subsection{Markov switching vector autoregression}

The last benchmark is the Markov switching vector autoregression model:

$$
\begin{gathered}
d d_{\boldsymbol{t}}=A^{c}\left(s_{t}\right)+\sum_{j=1}^{p} \boldsymbol{A}^{\boldsymbol{y} \cdot \boldsymbol{j}}\left(s_{t}\right) \boldsymbol{Y}_{\boldsymbol{t}-\boldsymbol{j}}+\sum_{j=1}^{p} \boldsymbol{A}_{\boldsymbol{t}}^{\boldsymbol{x} \cdot \boldsymbol{j}}\left(s_{t}\right) \boldsymbol{X}_{\boldsymbol{t}-\boldsymbol{j}}+A^{e .0}\left(s_{t}\right) \Delta \boldsymbol{e}_{t}+\boldsymbol{\varepsilon}_{\boldsymbol{t}} \\
\boldsymbol{\varepsilon}_{\boldsymbol{t}} \sim N\left(0, \boldsymbol{\Sigma}\left(s_{t}\right)\right) \\
P\left(s_{0}=i\right)=\pi_{0 i} ; i \in\{1,2, \ldots K\} \\
P\left(s_{t}=i \mid s_{t-1}=j\right)=\pi_{i j} ; i, j \in\{1,2, \ldots K\}
\end{gathered}
$$

where $P\left(s_{0}=i\right)$ - initial state probabilities, $P\left(s_{t}=i \mid s_{t-1}=j\right)$ - state transition probabilities, $K-$ number of regimes. We consider MSBVAR with 2 regimes.

To estimate this model, we use the MATLAB MS_Regress package proposed by (Perlin, 2015).

\footnotetext{
${ }^{9}$ We estimate this model by maximum likelihood using the TensorFlow 2.0 package.
} 


\section{The results}

The first observation we can make based on the obtained results is that the estimates of the fundamentalists' shares appear to be economically interpretable (see Figures 4-5 in Appendix B). Although the evolution of shares differs between the model specifications, they are generally at their highest in 2015-2017 meaning that the periods of higher volatility of exchange rate are associated with a high share of fundamentalists. This observation suggests that the time-varying link between dollarization and exchange rate dynamics (specifically its weakening in the period after the increase of exchange rate volatility) may be captured by the model. ${ }^{10}$ We proceed with formal examination (the forecasting exercise) of whether this approach would have been useful in real time.

To measure forecasting accuracy, we use RMSE values, evaluated as:

$$
\operatorname{RMSE}(h, m)=\left(\sum_{s=T 0}^{T 1}\left(y_{s}-f_{s}^{h}(m)\right)^{2}\right)^{0.5},
$$

where $f_{s}^{h}(m)=\sum_{k=1}^{h} d \widehat{d_{s-h}+k}(m) / h-$ mean forecast based on the model $m=1 . . M$. $T 0, T 1-$ the beginning and the end of the test sample, respectively. $y_{s}=\sum_{k=1}^{h} d d_{s-h+k} / h$ - true target variable value.

For all specifications listed above we calculate forecasts from September 2010 to the end of 2019 and compare out-of-sample forecasting performance for each benchmark. Table 1 reports each model's RMSE values divided by the ARX model's RMSE. For the shortest horizons the RMSE of the behavioral models is higher than that of the competitors, but starting from the 8-period horizon (i.e. 40-day ahead forecasts) the behavioral model with herding (BEH WG) has the highest forecasting accuracy. Notably, the best performing model on the short horizons (TVAR SF) also makes use of the parsimonious version of the behavioral approach by employing the naïve estimate of fundamentalists' share as the threshold variable. A more detailed analysis of the RMSE (presented in Appendix C) indicates that the overall success of the behavioral model is determined by its performance over the earlier periods of the forecast sample. This result is not unexpected and, arguably, reflects the ability of the behavioral elements to facilitate the model's faster adjustment to the new environment while the non-structural models

\footnotetext{
${ }^{10}$ We illustrate the differences in the dollarization developments implied by alternative strategies in Appendix D.
} 
require a relatively large number of observations to alter the parameters for the new regime.

Table 1. RMSE of the alternative models (as ratio to the RMSE of ARX).

\begin{tabular}{c|ccc|cc|c|cc}
$\begin{array}{c}\text { Forecast } \\
\text { Horizon }\end{array}$ & TVP AR & TVAR E & TVAR SF & LSTAR E & LSTAR SF & MSBVAR & BEH WG & BEH HERD \\
\hline $\mathbf{1}$ & 1.156 & 1.078 & 1.088 & 1.409 & 1.532 & 1.028 & 1.116 & 1.088 \\
$\mathbf{2}$ & 1.151 & 1.081 & 1.131 & 1.285 & 1.470 & 1.094 & 1.119 & 1.043 \\
$\mathbf{3}$ & 1.144 & 0.995 & 1.015 & 1.478 & 1.318 & $\mathbf{0 . 9 5 0}$ & 1.054 & 1.034 \\
$\mathbf{4}$ & 1.187 & 0.995 & 1.059 & 1.229 & 1.417 & $\mathbf{0 . 9 6 8}$ & 1.003 & 1.012 \\
$\mathbf{5}$ & 1.188 & 1.018 & 1.053 & 1.231 & 1.307 & $\mathbf{0 . 9 8 9}$ & 1.067 & 1.021 \\
$\mathbf{6}$ & 1.235 & 0.990 & 1.016 & 1.187 & 1.200 & $\mathbf{0 . 9 5 9}$ & 0.983 & 0.980 \\
$\mathbf{7}$ & 1.240 & 0.970 & 1.014 & 1.175 & 1.265 & $\mathbf{0 . 9 4 2}$ & 0.968 & 0.983 \\
$\mathbf{8}$ & 1.250 & 0.961 & 1.002 & 1.121 & 1.230 & 0.969 & $\mathbf{0 . 9 6 1}$ & 0.980 \\
$\mathbf{9}$ & 1.279 & 0.971 & 0.985 & 1.254 & 1.133 & 0.961 & $\mathbf{0 . 9 2 7}$ & 0.976 \\
$\mathbf{1 0}$ & 1.311 & 0.974 & 0.989 & 1.050 & 1.237 & 0.961 & $\mathbf{0 . 9 0 7}$ & 0.968 \\
$\mathbf{1 1}$ & 1.296 & 0.981 & 0.992 & 1.026 & 1.089 & 0.982 & $\mathbf{0 . 9 2 5}$ & 0.967 \\
$\mathbf{1 2}$ & 1.347 & 0.981 & 0.974 & 0.980 & 1.018 & 1.023 & $\mathbf{0 . 8 8 4}$ & 0.945 \\
\hline
\end{tabular}

\section{Conclusions}

Exchange rate depreciation rate is traditionally regarded as an important driver of households' deposit dollarization developments in emerging markets. However (as we may see ex-post) after the transition to a floating exchange rate regime this link weakened substantially in Russia.

We argue that the behavioral concepts that address the issue of agents' endogenous switching between strategies is an appropriate tool to employ in these circumstances. We demonstrated that by estimating an empirical model that features two types of exchange rate expectations formation. The adaptive extrapolating approach proves to be misleading in the noisy exchange rate environment and is abandoned in such periods. This result suggests that adopting a floating exchange rate regime stabilizes rather than amplifies fluctuations in dollarization. Importantly, we argue that with the help of the behavioral model such analysis could have been made in pseudo-real time and show that the model's forecasts are more accurate than those of the time series models during the transition to the floating exchange rate regime. 


\section{References}

Bank of Russia (2013). The history of the Bank of Russia's exchange rate policy. BIS papers 73, 293-299.

Barajas, A., Morales, R.A. (2003) Dollarization of liabilities: beyond the usual suspects. IMF Working Paper 03/11

Beal, M.J. (2003) Variational algorithms for approximate Bayesian inference (Doctoral dissertation, UCL (University College London)).

Di Guilmi, C., Gallegati, M., Landini, S. (2008). Economic dynamics with financial fragility and mean-field interaction: A model. Physica A: Statistical Mechanics and its Applications, 387(15), 3852-3861.

Di Guilmi, C., Gallegati, M., Landini, S., Stiglitz, J.E. (2020). An analytical solution for network models with heterogeneous and interacting agents. Journal of Economic Behavior \& Organization, 171(C), 189-220.

Di Narzo A., F., Aznarte, J. L. and Stigler, M (2009) tsDyn: Time series analysis based on dynamical systems theory. Mimeo

Feige, E.L. (2003) Dynamics of Currency Substitution, Asset Substitution and De Facto Dollarization and Euroization in Transition Countries. Comparative Economic Studies, 45, 358-383.

Franke, R., Westerhoff, F. (2012). Structural stochastic volatility in asset pricing dynamics: Estimation and model contest. Journal of Economic Dynamics \& Control, 36, 1193-1211

Honohan, P. (2007) Dollarization and exchange rate fluctuations. CEPR Discussion Paper 6205

Kamin, S.B., Ericsson, N.R. (2003) Dollarization in Post-Hyperinflationary Argentina. Journal of International Money Finance 22, 85-211. 
Khabibullin, R., Seleznev, S. (2020) Stochastic gradient variational Bayes with normalizing flows for estimation of macroeconomic models. Bank of Russia working paper series 61 .

Koop, G., Korobilis, D. (2013). Large time-varying parameter VARs. Journal of Econometrics, 177(2), 185-198.

Lamperti, F., Roventini, A., Sani, A. (2018). Agent-based model calibration using machine learning surrogates. Journal of Economic Dynamics and Control, 90, 366-389.

Lux, T. (2018). Estimation of agent-based models using sequential Monte Carlo methods. Journal of Economic Dynamics and Control, 91, 391-408.

Neanidis, K., Savva, C. (2009) Financial dollarization: short-run determinants in transition economies. Journal of Banking and Finance, 33, 1860-1873.

Perlin, M. (2015). MS_Regress-the Matlab package for markov regime switching models. Available at SSRN 1714016.

Ponomarenko, A., Solovyeva, A., Vasilieva, E. (2013) Financial dollarization in Russia: causes and consequences. Macroeconomics and Finance in Emerging Market Economies, 6(2), 221-243.

Rezende, D. J., Mohamed, S. (2015). Variational inference with normalizing flows. arXiv preprint arXiv:1505.05770.

Samreth, S. (2011) An Empirical Study on the Hysteresis of Currency Substitution in Cambodia. Journal of Asian Economics, 22(6), 518-527.

Valev, N.T. (2010) The Hysteresis of Currency Substitution: Currency Risk vs. Network Externalities. Journal of International Money and Finance, 29(2), 224-235.

Westerhoff, F. (2009) Exchange rate dynamics: a nonlinear survey. In: Rosser Jr., J.B.(Ed.), Handbook of Research on Complexity, Edward Elgar, Cheltenham, 287-325. 


\section{Appendix A. The naïve model}

We calculate the naïve fundamentalists' share as the restricted version of the equation (5).

Similar to the behavioral model, we assume the fundamentalists' $\left(d_{t}^{f}\right)$ and chartists' $\left(d_{t}^{c}\right)$ strategies as follows (assuming $\varphi=\chi=1$ ):

$$
\begin{aligned}
& d_{t}^{\text {f.naive }}=\left(e_{t-1}^{*}-e_{t-1}\right) \\
& d_{t}^{\text {c.naive }}=\left(e_{t-1}-e_{t-2}\right)
\end{aligned}
$$

The trend exchange rate $\left(e^{*}\right)$ is calculate as the 3-month moving average. The series of exchange rate depreciation rate $\left(e_{t-1}-e_{t-2}\right)$ and deviation from trend $\left(e_{t-1}^{*}-e_{t-1}\right)$ are standardized.

The strategies' fitness is defined equivalently:

$$
w_{t}^{\text {j.naive }}=w_{t-1}^{\text {j.naive }}+\left(e_{t-1}-e_{t-2}\right) d_{t-1}^{j . n a i v e} ; j=\{f, c\}
$$

The naïve fundamentalists; share therefore is defined as:

$$
s f_{t}^{\text {naive }}=\left(1+\exp \left(-\beta\left(w_{t}^{\text {f.naive }}-w_{t}^{\text {c.naive }}\right)\right)^{-1}\right.
$$

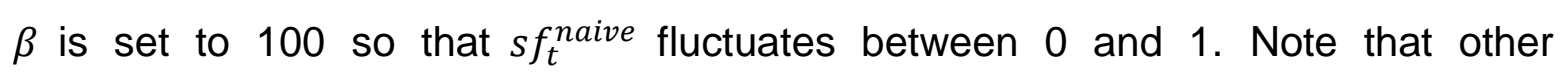
parameters' estimation is not required to calculate this measure and it may constructed recursively (i.e. the fundamentalists' share at time $t$ depends only on information on the exchange rate available at time $t-1$ ).

The resulting naïve estimates of the fundamentalists' share dynamics is presented in Figure 3. The results of this simple exercise indicate that after 2015 there is a significant increase in the fundamentalists' share. 
Figure 3. Naïve fundamentalists' share estimate

0,9

0,8

0,7

0,6

0,5

0,4

0,3

0,2

0,1

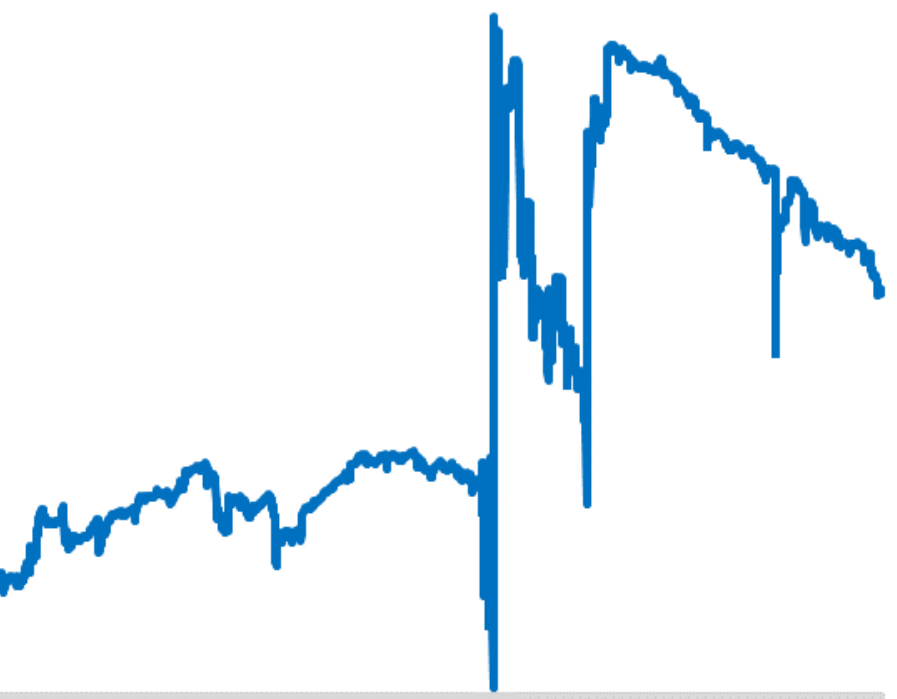

0

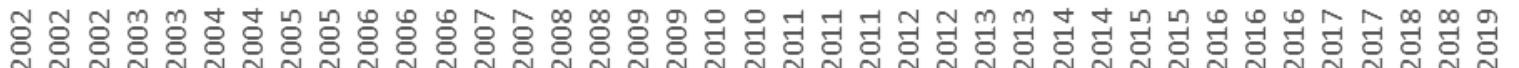
-

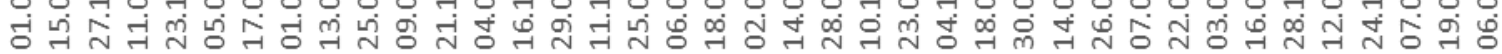




\section{Appendix B. Estimates of the agents' share}

Figure 4. Smoothed fundamentalists' shares in the case of WG specification (without herding). Red line depicts final smoothed estimate using the whole sample. Gray dotted lines depict recursive smoothed estimates on the expanding window.

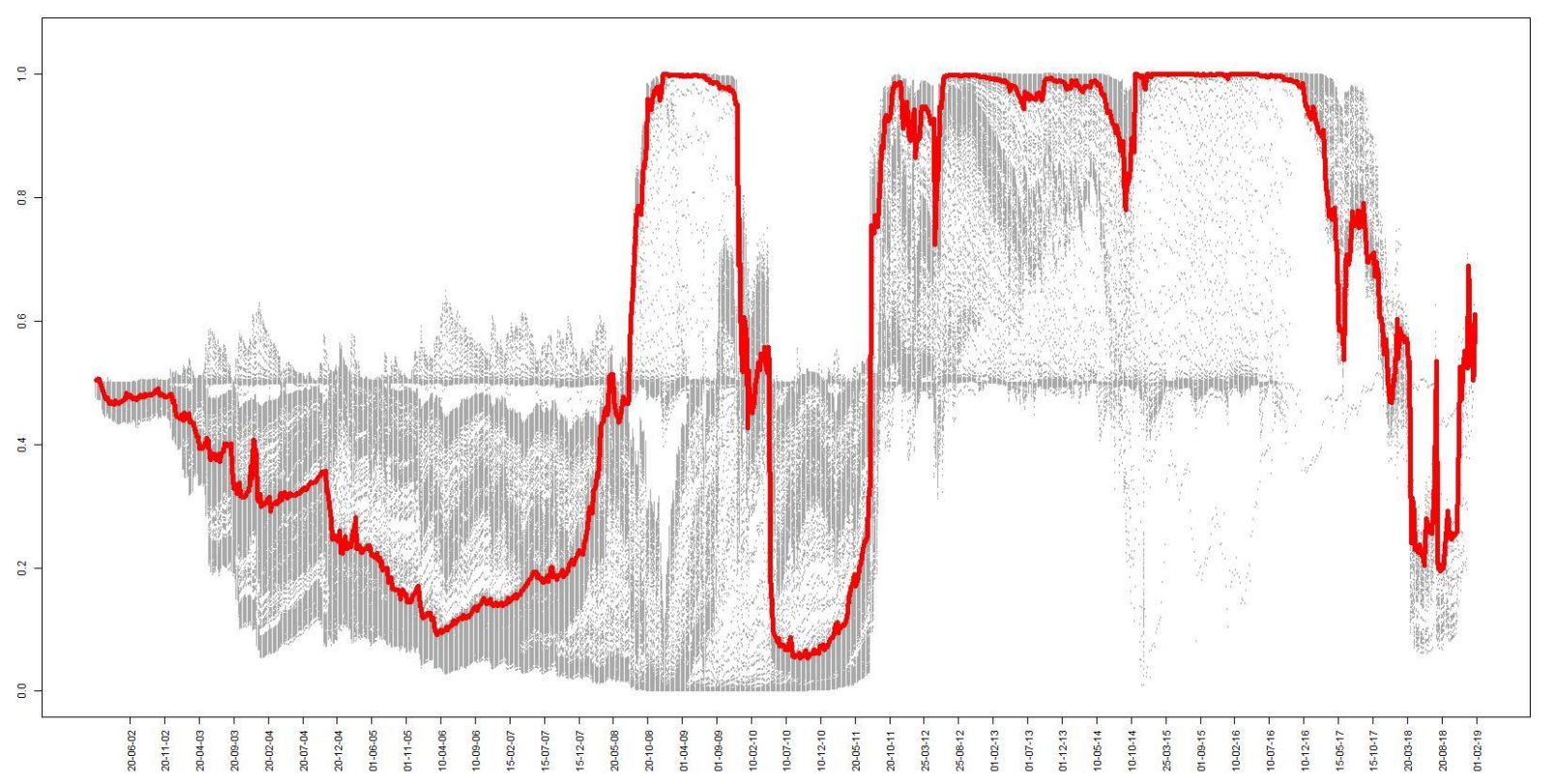

Figure 5. Smoothed fundamentalists' shares in the case of HERD specification (with herding). Red line depicts final smoothed estimate using the whole sample. Gray dotted lines depict recursive smoothed estimates on the expanding window.

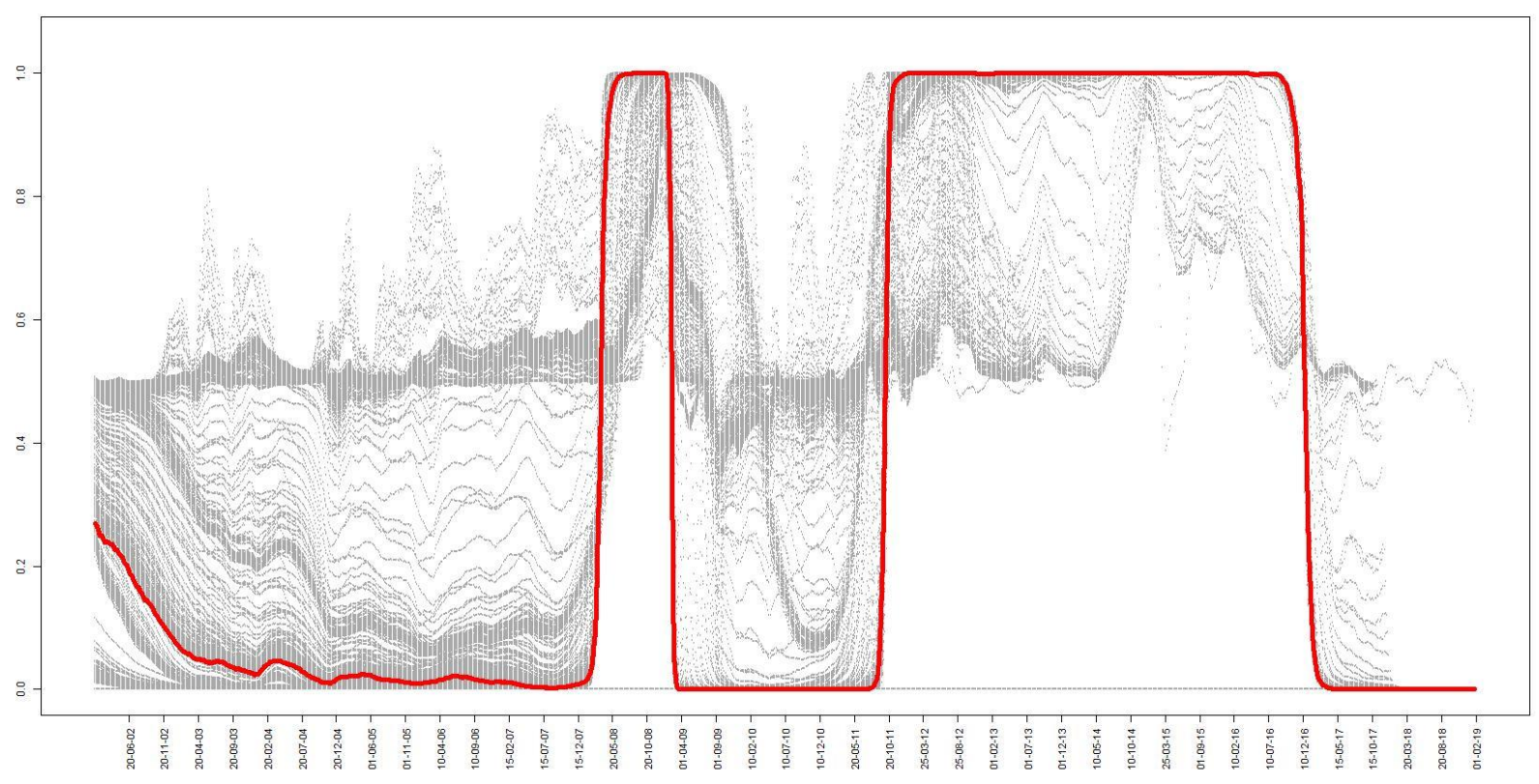




\section{Appendix C. RMSE measured over rolling windows}

In this section we present the RMSE values calculated over the rolling subsamples. We start with 20th September, 2009 and calculate the RMSE value for a 148observations long i.e. (approximately 2 year) window. We proceed by recursively shifting this window by 1 observation and calculate the RMSE values until the end of the test sample.

The RMSE measures (as a ratio to the RMSE of the ARX model) for different forecast horizons $(h)$ are presented in Figures 6-8. The date is the last observation of the corresponding rolling window

Each model was used to forecast $\mathrm{f}_{\mathrm{s}}=\sum_{\mathrm{k}=1}^{h} \widehat{\mathrm{dd}_{\mathrm{t}+\mathrm{k}}} / h$.

RMSE was evaluated as $\left(\sum_{\mathrm{s}=\mathrm{t}}^{\mathrm{t}+2 \text { years }}\left(\mathrm{y}_{\mathrm{s}}-\mathrm{f}_{\mathrm{s}}\right)^{2}\right)^{0.5}$, where $\mathrm{y}_{\mathrm{s}}=\sum_{\mathrm{k}=1}^{h} \mathrm{dd}_{\mathrm{t}+\mathrm{k}} / h-$ actual dollarization.

Figure 6. RMSE measured over rolling windows for the 3 period forecasting horizon.

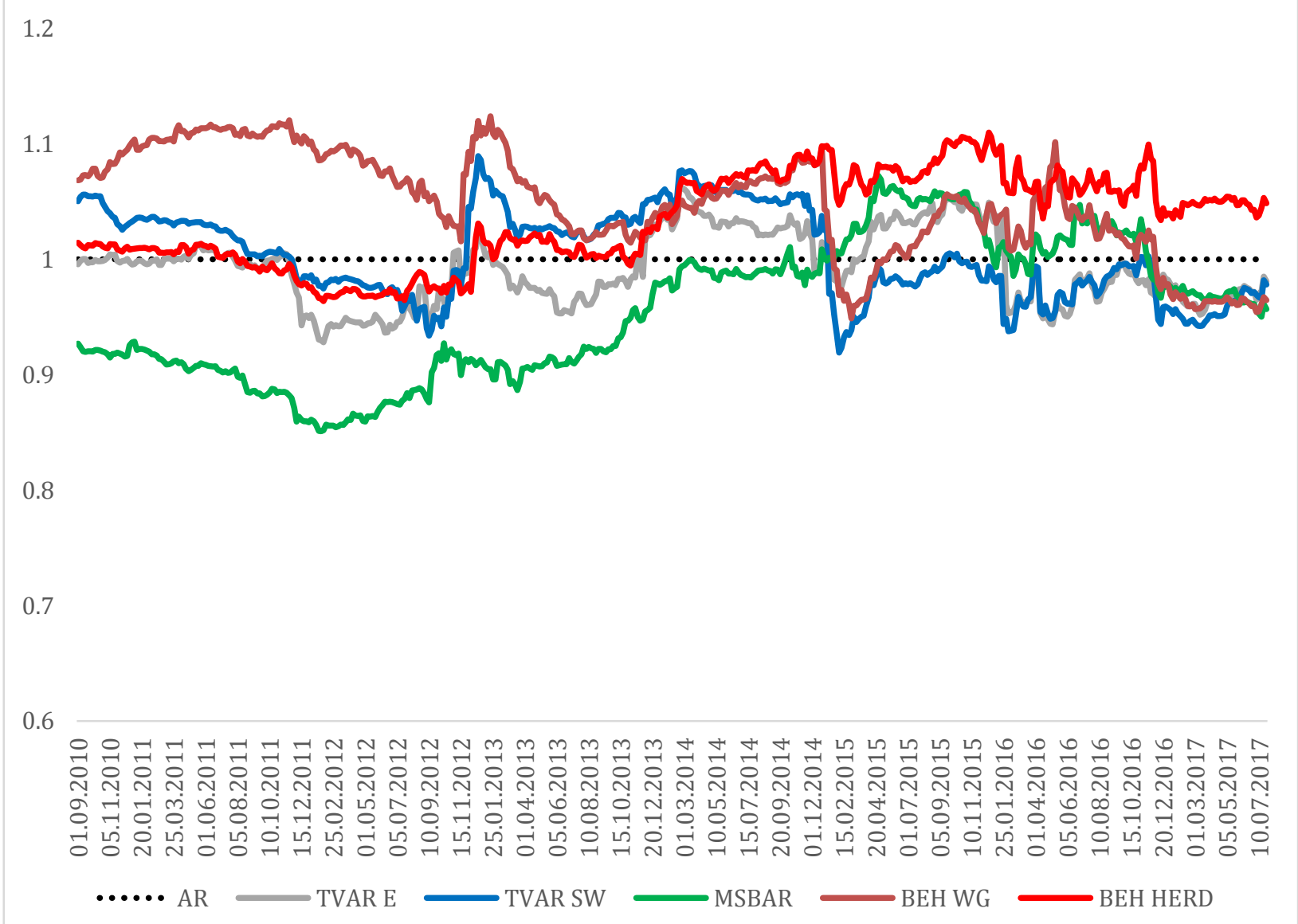


Figure 7. RMSE measured over rolling windows for the 6 period forecasting horizon.

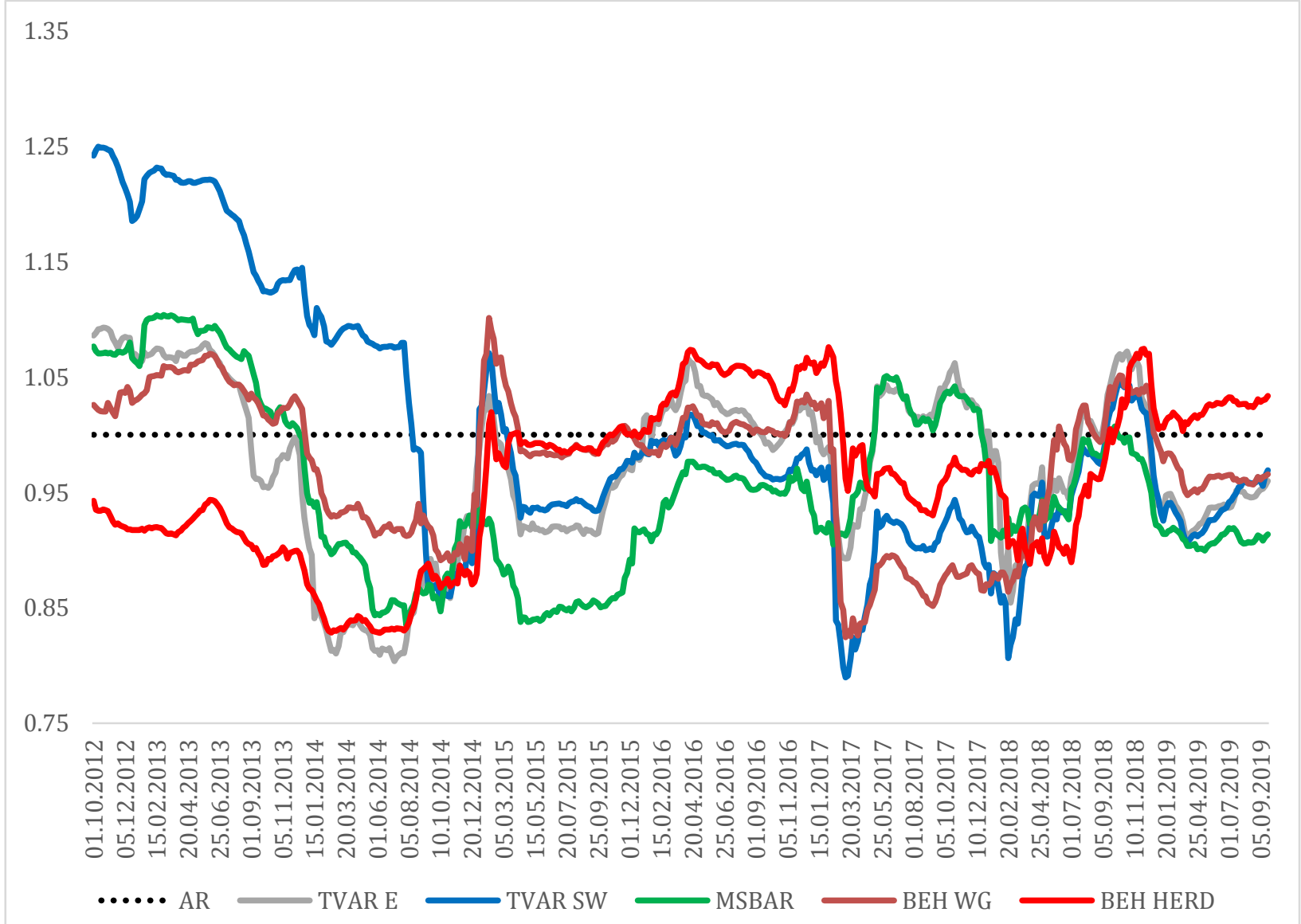

Figure 8. RMSE measured over rolling windows for the 12 period forecasting horizon.

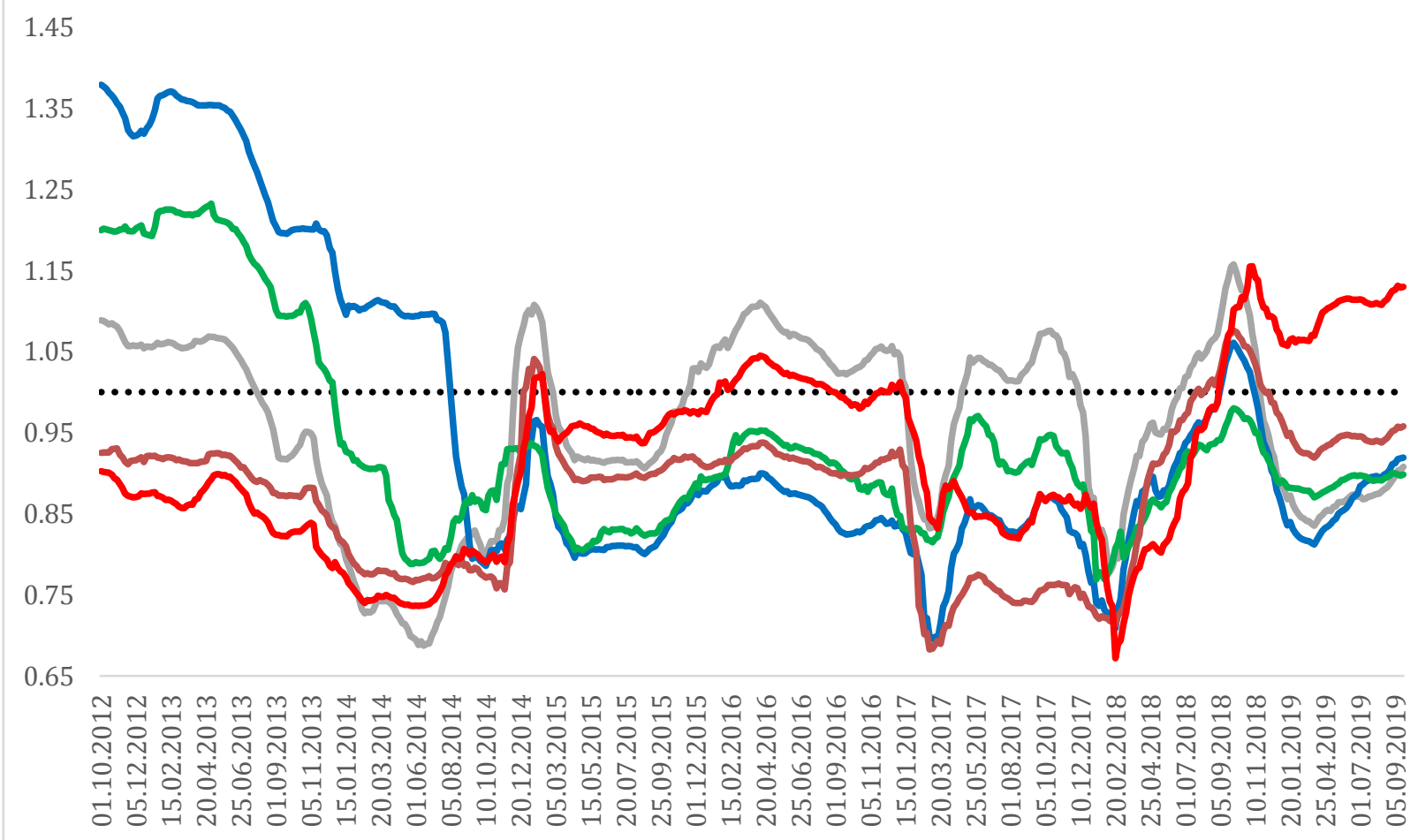
...... AR
- TVAR E
TVAR SW
MSBAR
BEH WG
BEH HERD 


\section{Appendix D. Comparison of dollarization changes implied by alternative strategies}

In order to illustrate the differences in behavior implied by the alternative strategies we calculate the conditional forecasts of changes in dollarization separately for each agent type. Specifically, we use (1) and (2) for fundamentalists' strategy and (3) for chartists:

$d_{t+h}^{f}=\alpha^{f}+\varphi\left(e_{t+h}^{*}-e_{t+h}\right)+\sum_{j=1}^{p}\left(b_{o i l . j}^{f} \pi_{t+h-j}^{o i l}+b_{s e n t . j}^{f} s_{t+h-j}\right)$

$e_{t+h}^{*}=e_{t+h-1}^{*}+v_{t+h}^{e *} ; \quad v_{t+h}^{e *} \sim N\left(0, \sigma_{e *}^{2}\right)$

(2)

$d_{t+h}^{c}=\alpha^{c}+\chi\left(e_{t+h}-e_{t+h-1}\right)+\sum_{j=1}^{p}\left(b_{o i l . j}^{c} \pi_{t+h-j}^{o i l}+b_{\text {sent.j }}^{c} s_{t+h-j}\right)$

All parameters are recursively estimated similarly to the main forecasting exercise. It means that h-step forecast $d_{t+h}^{\text {type }}$, type $=\{c, f\}$ contains parameters, estimated using the information available at time $t$. Fundamental exchange rate $e_{t+h}^{*}$ is smoothed value estimated using all exchange rate data up to $t+12$.

All exogenous variables $\left(\pi_{t+h-j}^{o i l}, s_{t+h-j}, e_{t+h}, e_{t+h-1}, \forall 1 \leq j \leq 3\right)$ are equal to their observed values.

The results are presented in Figures 9-10 and demonstrate substantial differences in the dollarization developments implied by alternative strategies.

Figure 9. BEH WG model forecasts for the 12 period forecasting horizon.

0.5

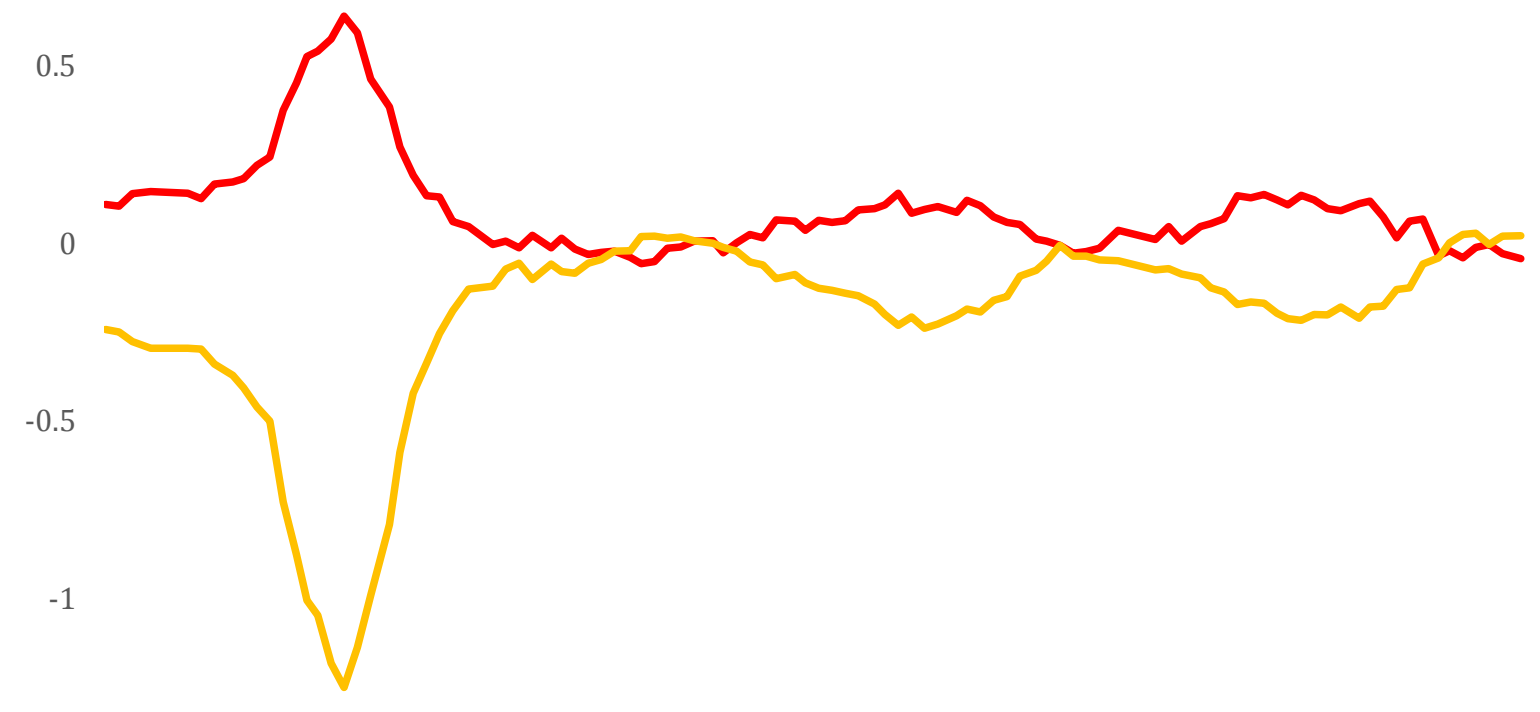

$-1.5$ 
Figure 10. BEH HERD model forecasts for the 12 period forecasting horizon

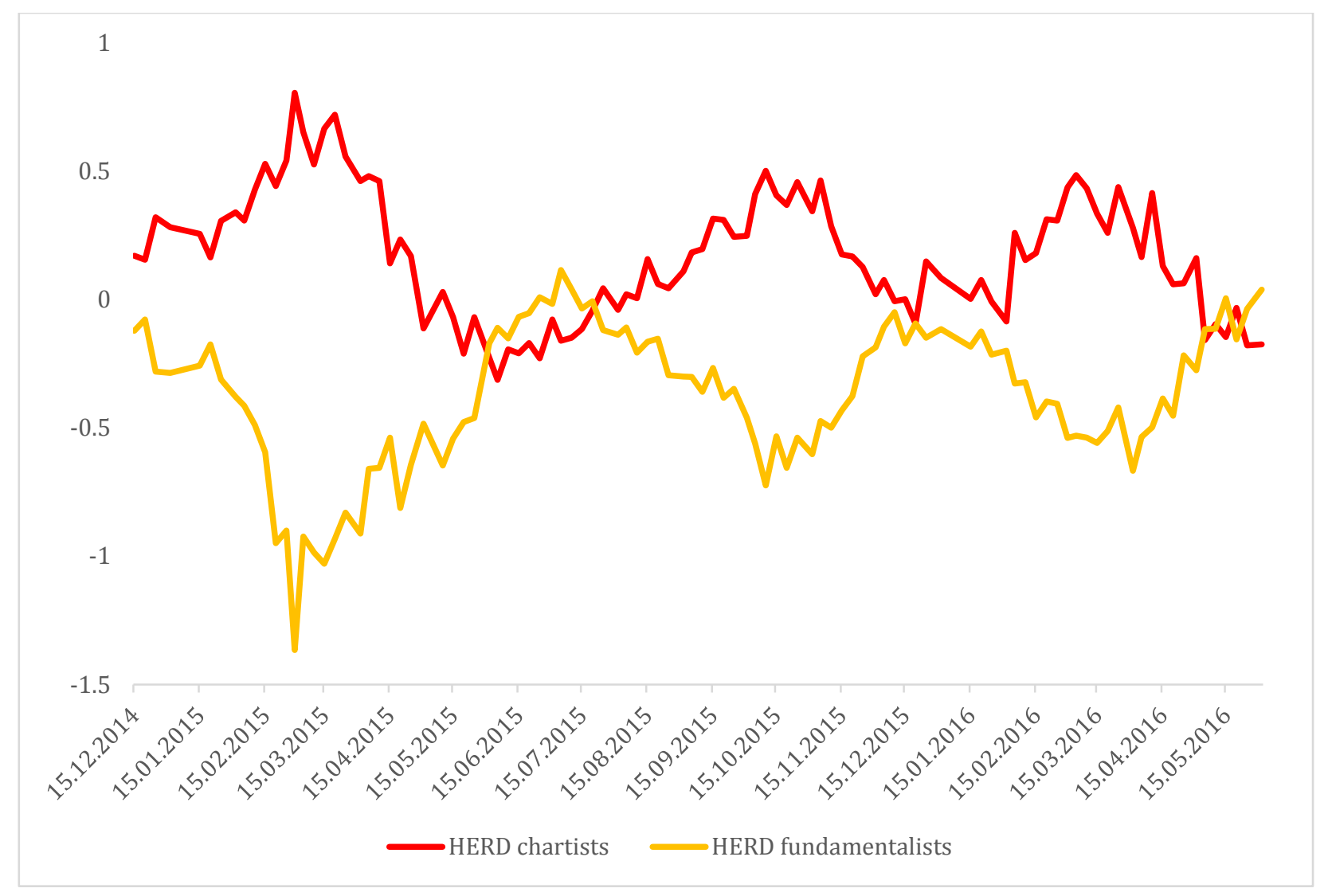

